\title{
Effects of Oxygen Partial Pressure on Wood-Based Activated Carbon Treated with Vacuum Ultraviolet Light
}

\author{
Nana Takahashi ${ }^{1}$, Hiroyuki Kuwae ${ }^{2}{ }^{\circledR}$, Seren Maeda ${ }^{1}$, Masahiro Kawamura ${ }^{1}$, Ami Tezuka ${ }^{1}$, Shuichi Shoji ${ }^{1}$ and \\ Jun Mizuno 2,3,* \\ 1 Department of Electronic and Physical Systems, Waseda University, Shinjuku 169-8555, Japan; \\ takahashi@shoji.comm.waseda.ac.jp (N.T.); maeda@shoji.comm.waseda.ac.jp (S.M.); \\ kawamura@shoji.comm.waseda.ac.jp (M.K.); tezuka@shoji.comm.waseda.ac.jp (A.T.); shojis@waseda.jp (S.S.) \\ 2 Research Organization for Nano and Life Innovation, Waseda University, 513 Waseda Tsurumaki, \\ Shinjuku 162-0041, Japan; kuwae@shoji.comm.waseda.ac.jp \\ 3 Organization for Regional Collaborative Research and Development, Tokyo University of Science, Chino, \\ Nagano 391-0292, Japan \\ * Correspondence: mizuno@waseda.jp; Tel.: +81-3-5286-8324
}

check for updates

Citation: Takahashi, N.; Kuwae, H.; Maeda, S.; Kawamura, M.; Tezuka, A.; Shoji, S.; Mizuno, J. Effects of Oxygen Partial Pressure on Wood-Based Activated Carbon Treated with Vacuum Ultraviolet Light. Coatings 2021, 11, 411. https://doi.org/ 10.3390/coatings11040411

Received: 15 March 2021 Accepted: 30 March 2021 Published: 1 April 2021

Publisher's Note: MDPI stays neutral with regard to jurisdictional claims in published maps and institutional affiliations.

Copyright: (c) 2021 by the authors. Licensee MDPI, Basel, Switzerland. This article is an open access article distributed under the terms and conditions of the Creative Commons Attribution (CC BY) license (https:// creativecommons.org/licenses/by/ $4.0 /)$.

\begin{abstract}
This study uses vacuum ultraviolet (VUV) light with a wavelength of $172 \mathrm{~nm}$ as a surface treatment to enhance the adsorption capacity of wood-based activated carbon (AC). The AC surface treatment is performed under three $\mathrm{O}_{2}$ partial pressure conditions- $5.0 \times 10^{4} \mathrm{~Pa}$, where ozone $\left(\mathrm{O}_{3}\right)$ effects dominate; $6.3 \times 10^{-6} \mathrm{~Pa}$, where VUV effects dominate; and $1.9 \times 10^{3} \mathrm{~Pa}$ for a balanced condition. For the $\mathrm{O}_{3}$-dominant condition, only graphene edge defects are etched (no aromatic carbon bonds are etched), resulting in increased surface roughness. When the VUV effects dominate, aromatic carbon bonds are cleaved, which then reacted with $\mathrm{O}_{2}$ or water adsorbed inside the pores. This increased both the number and size of the mesopores. Under the balanced conditions, the water adsorption capacity was enhanced by $45.5 \%$, which is higher than that obtained before VUV exposure or with VUV under other conditions. This is because the surface roughness increased, as well as the pore sizes and numbers under the balanced condition. These results indicate that we can control VUV-based AC surface treatments via $\mathrm{O}_{2}$ partial pressure.
\end{abstract}

Keywords: activated carbon; vacuum ultraviolet; porous structure; surface treatment; characterization; water adsorption capacity

\section{Introduction}

Activated carbon (AC) has high surface areas and adsorption capacities because of oxygen functional groups on the surfaces of micro- and mesoporous structures $[1,2]$. The porous properties of AC are widely used for water purification, gas filtering, and gas adsorption [3-6]. In addition, the electrical conductivity of the $s p^{2}$ carbons enables other potential applications, such as electrodes for electronic and electrochemical devices [7] and double-layer capacitors [8].

The AC structure derives from the nature of the precursor materials, which could be chemical products (coal, polymers), or natural products (palm shells, crops, wood) [9,10]. Natural-material-based AC is renewable, abundant, and has natural pores [11]. It requires a binder to form shapes, which can degrade the properties by filling the pores and also degrade the electrical conductivity [6]. Previously, we developed a thin binder-less wood-based AC, a film of woody carbon material (FWCM), that has natural pore structures. It originated from Picea jezoensis (Jezo Spruce) and had an electrical conductivity of $3 \times 10^{-2} \mathrm{~S} / \mathrm{m}$ [8]. FWCM has a unique physical characteristic (thinness, flexibility), although the adsorption characteristic is inferior to chemical products-based AC as same as other wood-based AC. Thus, surface treatment to improve adsorption characteristics is required for wood-based $\mathrm{AC}$. 
After the AC structure is formed, oxygen functional groups on the surfaces are created by various treatments to improve its adsorption capacity. There are two major treatment methods. One is a wet treatment that uses acid solutions [9-14]; the other is a dry treatment that uses a plasma $[15,16]$ or high-energy light, such as ultraviolet (UV) $[17,18]$. In the wet treatment, the acid solution consists of $\mathrm{HNO}_{3}$ or $\mathrm{H}_{2} \mathrm{O}_{2}$ to form oxygen functional groups via strong oxidation reactions on the outer and inner AC surfaces [19]. However, these solutions generate hazardous wastes and can disrupt the pore structures [13]. In dry treatments, $\mathrm{O}_{2}$ gas is used. Only the outer AC surface is gently oxidized, and oxygen functional groups are created by excited oxygen atoms $\mathrm{O}\left({ }^{1} \mathrm{D}\right)$ or ozone $\left(\mathrm{O}_{3}\right)$ generated by electrical plasmas or UV light. Thus, dry treatments retain pore structures while introducing oxygen functional groups on the surfaces [13]. Vacuum ultraviolet (VUV) surface treatments, such as those that use $172-\mathrm{nm} \mathrm{Xe}_{2}{ }^{*}$ excimer lamps $(698 \mathrm{~kJ} / \mathrm{mol})$, utilize much higher energy than those that use 254-nm UV light from a mercury lamp (472 kJ/mol). In a 172-nm VUV treatment, the light is strongly absorbed by $\mathrm{O}_{2}$, generating high densities of $\mathrm{O}_{3}$, which is hardly dissociated by the VUV [20]. In addition, the VUV directly cleaves chemical bonds, such as $\mathrm{O}-\mathrm{H}(458 \mathrm{~kJ} / \mathrm{mol})$ and $\mathrm{C}=\mathrm{C}(589 \mathrm{~kJ} / \mathrm{mol})$, which are difficult to break via UV light. We previously reported a VUV treatment of FWCM under an $\mathrm{O}_{2}$ partial pressure of $5.0 \times 10^{4} \mathrm{~Pa}$ [8], which enhanced the iodine adsorption capacity by $21.2 \%$. However, the effects of the VUV treatment were a tradeoff between $\mathrm{O}_{3}$ and VUV effects, depending on the $\mathrm{O}_{2}$ partial pressure. Hence, the effect of the $\mathrm{O}_{2}$ partial pressure on the AC treatment had not been clarified.

Here, we examined the $\mathrm{O}_{2}$ effects on the VUV treatment of AC. The FWCM was, thus, treated at several $\mathrm{O}_{2}$ partial pressures: $5.0 \times 10^{4} \mathrm{~Pa}$, where activated oxygen $\left(\mathrm{O}_{3}\right)$ effects dominate, $1.9 \times 10^{3}$ Pa where the VUV effects dominate, and $6.3 \times 10^{-6}$ Pa for a balanced condition. The mechanisms are discussed in terms of chemical and physical characteristics, including water adsorption.

\section{Experiments}

\subsection{Materials}

The FWCM was prepared from raw wood (Picea jezoensis) purchased from the Durart Company (Saitama, Japan). It was carbonized at $300^{\circ} \mathrm{C}$ for six hours to form a film without cracks, then heated to $750{ }^{\circ} \mathrm{C}$ for $30 \mathrm{~min}$ to enhance the adsorption capacity by improving the porous structure [8]. The FMCM was sliced along the tracheid into $100-\mu \mathrm{m}$-thick pieces.

\subsection{VUV Treatment}

VUV treatment was performed with a 172-nm $\mathrm{Xe}_{2}{ }^{*}$ excimer lamp (UER20-172, Ushio, Japan) [8]. The samples were placed in a treatment chamber, and the $\mathrm{O}_{2}$ partial pressure was introduced. The sample was then irradiated with VUV light for ten minutes, after which the chamber was purged with $\mathrm{N}_{2}$ gas. The sample was then irradiated with VUV for $10 \mathrm{~min}$ with the irradiance of $10 \mathrm{~mW} / \mathrm{cm}^{2}$ at room temperature, after which the chamber was purged with $\mathrm{N}_{2}$ gas. The distance between the light source and the samples was $1.3 \mathrm{~cm}$ [8]. The size and thickness of the samples were not changed before and after the treatment.

For each of the conditions $\left(\mathrm{O}_{3}\right.$-dominant, direct VUV-dominant, and balanced), the three different $\mathrm{O}_{2}$ partial pressures were calculated using the following Equation (1) [20]:

$$
I=I_{0} \times \exp \left(-\alpha P_{\mathrm{O} 2} L\right)
$$

where $I_{0}$ is the light intensity from the VUV source, $I$ is the VUV intensity on the sample surface, $\alpha$ is the VUV absorption efficiency of $\mathrm{O}_{2}, P_{\mathrm{O} 2}$ is the $\mathrm{O}_{2}$ partial pressure, and $L$ is the distance from the light source to the sample (for details, see Figure A1 in the Appendix A). We determined the following three conditions: High $P_{\mathrm{O} 2}\left(5.0 \times 10^{4} \mathrm{~Pa}\right)$, where $100 \%$ of the light energy was used for $\mathrm{O}_{3}$ generation; low $P_{\mathrm{O} 2}\left(6.3 \times 10^{-6} \mathrm{~Pa}\right)$, where $0 \%$ of the light energy directly reached the sample surface, and median $P_{\mathrm{O} 2}\left(1.9 \times 10^{3} \mathrm{~Pa}\right)$, where $60.7 \%$ of the light energy was used for $\mathrm{O}_{3}$ generation, and $39.3 \%$ directly reached the sample surface. 


\subsection{Characterizations}

\subsubsection{Chemical Analysis}

X-ray photoelectron spectroscopy (XPS, JPS-9100 TR, Tokyo, Japan) was used to examine the oxygen content and functional groups on the FWCM surfaces. The spectra were obtained using $\mathrm{Mg} \mathrm{K} \alpha(1253.6 \mathrm{eV})$ radiation. The $\mathrm{C} 1$ s electron binding energy was calibrated at $284.0 \mathrm{eV}$. The accelerating voltage and current were $10 \mathrm{kV}$ and $10 \mathrm{~mA}$, respectively, and the pass energy was $10 \mathrm{eV}$. The spectra were analyzed with a GaussianLorentzian function in curve-fitting software (SpecSurf 1.92). A mixing ratio of 0.7 was used for all peaks.

\subsubsection{Physical Analysis}

The surface morphologies of the samples were imaged with a scanning electron microscope (SEM; S-5500 and SU-8200, Hitachi High technologies, Tokyo, Japan). No conductive coatings were used, and the images were acquired rapidly to minimize damage by the electron beam.

Specific surface areas and pore volumes were calculated from $\mathrm{CO}_{2}$ gas adsorption using a Microtraek-MRB (Belsorp-HP, MicrotracBEL, Osaka, Japan). $\mathrm{N}_{2}$ gas was not used because it cannot diffuse into the interior of carbon materials that have complex pore structures, such as the hierarchical structure of woody carbon [21]. Conversely, $\mathrm{CO}_{2}$ can easily adsorb on the pore structures because of its large quadrupole moment [21]. The sample (about $0.2 \mathrm{~g}$ ) was ground into a powder and degassed at $473 \mathrm{~K}$ for $20 \mathrm{~h}$ to remove water and other atmospheric contaminants. The micropore size distribution was analyzed based on Horvath-Kawazoe (HK) method. Specific surface areas and micropore volumes were derived from $\mathrm{CO}_{2}$ adsorption isotherms using standard Brunauer-Emmett-Teller analysis [21].

\subsubsection{Water Adsorption}

Water adsorption experiments were performed at room temperature to evaluate the adsorption capacity of untreated and treated FWCM. As a reference, commercial silica-gel desiccant was also evaluated. All samples were placed in a $20 \%$ relative-humidity environment for $24 \mathrm{~h}$ after degassing at $170^{\circ} \mathrm{C}$ for $6 \mathrm{~h}$. It is well known that sulfuric acid solution controls relative humidity according to the concentration, since it is hygroscopic [22]. The relative-humidity was controlled by using aqueous solution system that offers a degree of humidity adjustment that can be achieved by changing its concentration [22]. To keep relative-humidity at $20 \%, 58.9 \mathrm{wt} . \% \mathrm{H}_{2} \mathrm{SO}_{4}$ solution was placed in the chamber. The adsorption rate $(A)$ was calculated according to:

$$
A=\frac{W-W_{0}}{W_{0}} \times 100
$$

where $W$ and $W_{0}$ are the initial and the final sample weights, respectively.

\section{Results and Discussions}

\subsection{Chemical Properties}

XPS analysis was conducted with respect to oxygen content and functional groups to examine the chemical effects on the FWCM from the VUV treatments. Table 1 lists the atomic ratios of carbon and oxygen $(\mathrm{O} / \mathrm{C})$ from the $\mathrm{C} 1 \mathrm{~s}$ and $\mathrm{O} 1$ s spectra. The $\mathrm{O} / \mathrm{C}$ ratio for untreated FWCM was $4.6 \%$, while those for the high $P_{\mathrm{O} 2}$, median $P_{\mathrm{O} 2}$, and low $P_{\mathrm{O} 2}$ conditions were $26.6 \%, 27.8 \%$, and $24.8 \%$, respectively. The oxygen content was, thus, significantly enhanced after all the VUV treatments, especially for the high and median $P_{\mathrm{O} 2}$. Figure 1 shows $\mathrm{C} 1 \mathrm{~s}$ spectra for the FWCMs. For all the prepared samples, the $\mathrm{C} 1 \mathrm{~s}$ spectra could be resolved into three component peaks for $\mathrm{C}=\mathrm{C} / \mathrm{C}-\mathrm{C}(284.2 \mathrm{eV}), \mathrm{C}=\mathrm{O} / \mathrm{C}-\mathrm{O}$ $(284.9-285.3 \mathrm{eV})$, and $\mathrm{O}-\mathrm{C}=\mathrm{O}(287.0-288.1 \mathrm{eV})$ [8]. The relative content of each group is listed in Table 2. The $\mathrm{C}=\mathrm{C} / \mathrm{C}-\mathrm{C}$ group is attributed to an aromatic ring layer, which is the main AC component [23]. After the VUV treatments, the $\mathrm{C}=\mathrm{C} / \mathrm{C}-\mathrm{C}$ groups decreased, and 
oxygen functional groups increased. Furthermore, the $\mathrm{C}=\mathrm{O} / \mathrm{C}-\mathrm{O}$ groups exhibited higher peak areas than the $\mathrm{O}-\mathrm{C}=\mathrm{O}$ groups after the high $P_{\mathrm{O} 2}$ treatment. In contrast, the $\mathrm{O}-\mathrm{C}=\mathrm{O}$ groups increased by a factor of two, compared with values before the VUV treatments, after median and low $P_{\mathrm{O} 2}$, while the $\mathrm{C}=\mathrm{O} / \mathrm{C}-\mathrm{O}$ groups decreased.

Table 1. Oxygen and carbon composition of untreated and vacuum-ultraviolet-treated films of woody carbon material calculated from C1s and O1s X-ray photoelectron spectra.

\begin{tabular}{ccc}
\hline \multirow{2}{*}{ Samples } & \multicolumn{3}{c}{ Composition } \\
\cline { 2 - 3 } & O [at.\%] & C [at.\%] \\
\hline Untreated & 4.58 & 95.4 \\
High $P_{\mathrm{O} 2}$ & 21.0 & 79.0 \\
Middle $P_{\mathrm{O} 2}$ & 21.8 & 78.2 \\
Low $P_{\mathrm{O} 2}$ & 19.9 & 80.1 \\
\hline
\end{tabular}
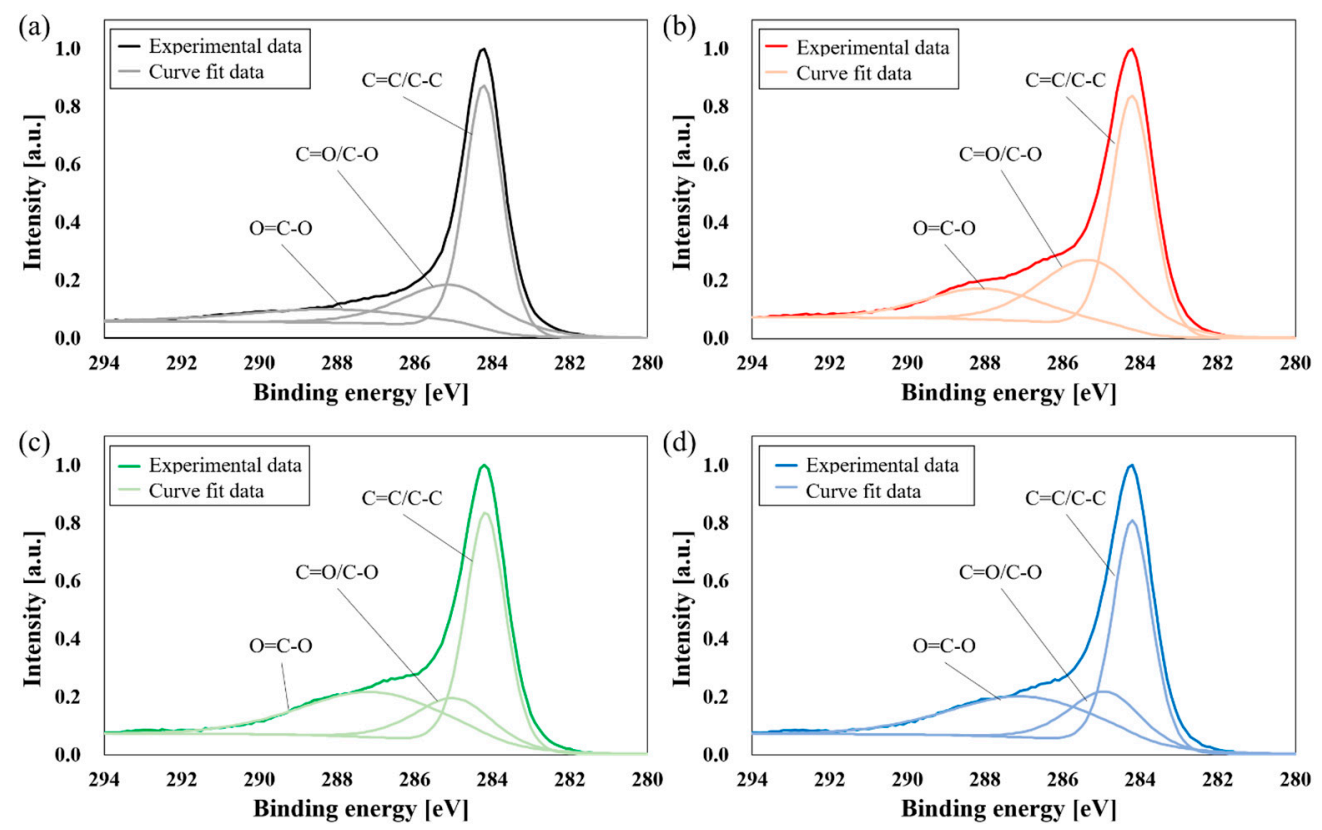

Figure 1. C1s X-ray photoelectron spectra of (a) untreated and vacuum-ultraviolet-treated films of woody carbon material under (b) high $P_{\mathrm{O} 2},(\mathbf{c})$ median $P_{\mathrm{O} 2}$, and (d) low $P_{\mathrm{O} 2}$.

Table 2. Chemical components of untreated and vacuum-ultraviolet-treated films of woody carbon material calculated from C1s X-ray photoelectron spectra.

\begin{tabular}{cccc}
\hline Samples & $\mathbf{C}=\mathrm{C} / \mathrm{C}-\mathrm{C}[\%]$ & $\mathbf{C}=\mathbf{O} / \mathbf{C}-\mathbf{O}[\%]$ & O-C=O [\%] \\
\hline Untreated & 58.4 & 26.6 & 15.1 \\
High $P_{\mathrm{O} 2}$ & 49.2 & 32.2 & 18.6 \\
Middle $P_{\mathrm{O} 2}$ & 48.2 & 18.1 & 33.7 \\
Low $P_{\mathrm{O} 2}$ & 47.3 & 20.0 & 32.7 \\
\hline
\end{tabular}

Differences in the oxygen functional groups after various VUV conditions were observed. Although $\mathrm{O}_{3}$ is the main reactant when FWCM is treated with VUV and high $P_{\mathrm{O} 2}$, graphene is difficult to oxidize [24]. Thus, the $\mathrm{O}_{3}$ only reacts with $\mathrm{H}$ atoms at graphene edge defects $[25,26]$, generating $\mathrm{C}-\mathrm{O}$ groups. The $\mathrm{C}-\mathrm{O}$ addition reaction is the dominant pathway relative to the $\mathrm{O}-\mathrm{C}=\mathrm{O}$ generation reaction during the oxidation of carbon chains at room temperature [27]. However, the VUV generates radical sites by cleaving graphene bonds $(518 \mathrm{~kJ} / \mathrm{mol})[28,29]$, and those sites can react with $\mathrm{O}_{2}$ and $\mathrm{H}_{2} \mathrm{O}$ adsorbed in the 
pores. Thus, the $\mathrm{O}=\mathrm{C}-\mathrm{O}$ groups increase by the progression of the oxidation reaction at low $P_{\mathrm{O} 2}$.

\subsection{Physical Properties}

Figure 2 shows SEM images of FWCM surfaces before and after VUV treatment. Large pieces of debris were observed that originated from the natural wood, and there were no significant differences before and after the treatment. Thus, as with plasma treatments, the VUV does not affect the AC macro structures $[15,16]$. Figure 3 shows high-magnification SEM images of FWCMs. A smooth surface with mesopores was observed for the untreated FWCM [Figure 3a]. The pores were either naturally derived from the wood or generated during carbonization. After a high $P_{\mathrm{O} 2}$ treatment, the mesopores were disappeared on the surface, and the surface roughness increased [Figure 3b], which was consistent with previous reports [8]. In contrast, after a low $P_{\mathrm{O} 2}$ treatment, the mesopore size grew to over $10 \mathrm{~nm}$, and the number of pores increased [Figure 3c]. After a median $P_{\mathrm{O} 2}$ treatment, the pores enlarged and increased in number compared with a high $P_{\mathrm{O} 2}$ treatment, and the surface roughness increased as well compared with low $P_{\mathrm{O} 2}$ treatment [Figure $3 \mathrm{~d}$ ].

(a)

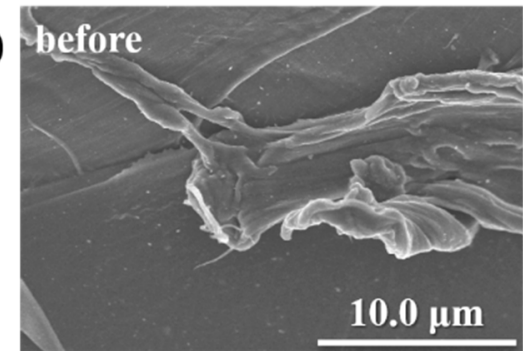

(b)

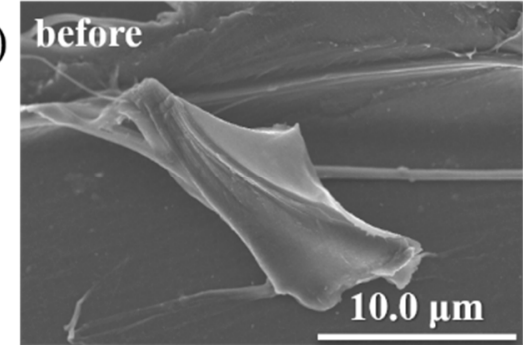

(c)

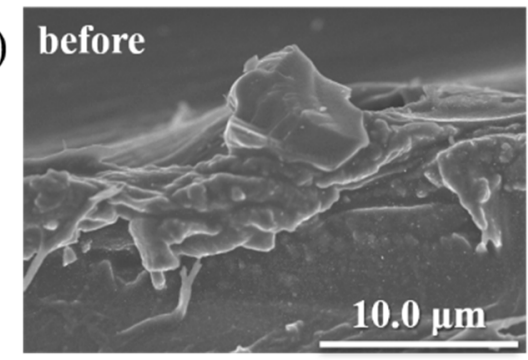

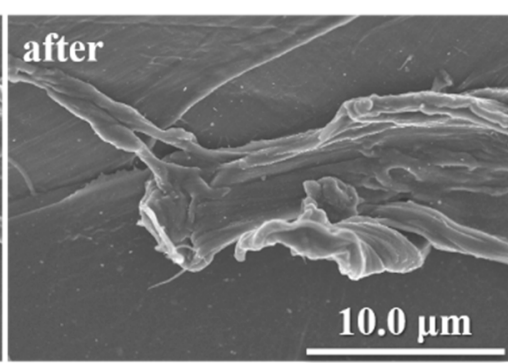
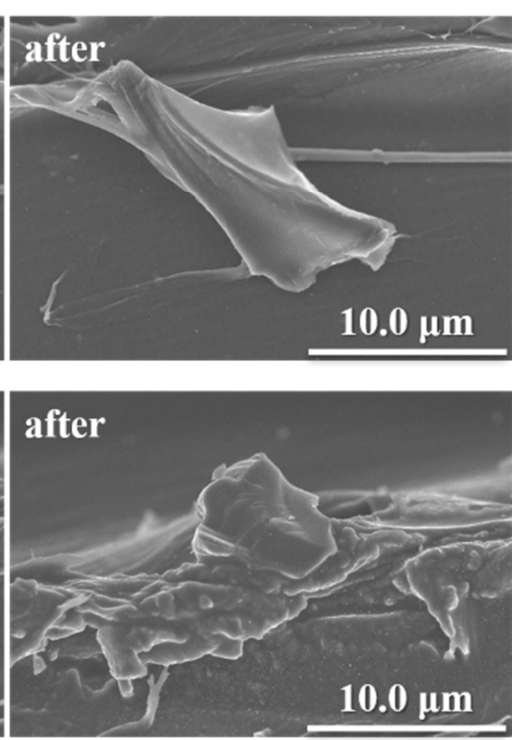

Figure 2. Low-magnification scanning electron microscope images of films of woody carbon material before and after vacuum-ultraviolet-treatments under $(\mathbf{a})$ high $P_{\mathrm{O} 2},(\mathbf{b})$ median $P_{\mathrm{O} 2}$, and (c) low $P_{\mathrm{O} 2}$.

During the VUV treatment, the AC surface is modified by $\mathrm{O}_{3}$ or the VUV, depending on the $\mathrm{O}_{2}$ partial pressure. At high $P_{\mathrm{O} 2}$, the high density of generated $\mathrm{O}_{3}$ etched only the graphene edges, as discussed in the XPS results, which increased the surface roughness. At low $P_{\mathrm{O} 2}$, the VUV cleaved carbon bonds and generated radical sites that reacted with adsorbed $\mathrm{O}_{2}$ or $\mathrm{H}_{2} \mathrm{O}$ in the meso- and micropores. Thus, the number and the size of the mesopores increased at low $P_{\mathrm{O} 2}$. At median $P_{\mathrm{O} 2}$, some VUV is absorbed by the $\mathrm{O}_{2}$, and some reaches the sample surface. Thus, both surface roughness and the increased mesopore size and number occurred simultaneously. Overall, these results indicate that 
VUV can control the AC surface roughness and pore density/number only by changing the $\mathrm{O}_{2}$ partial pressure.

(a)

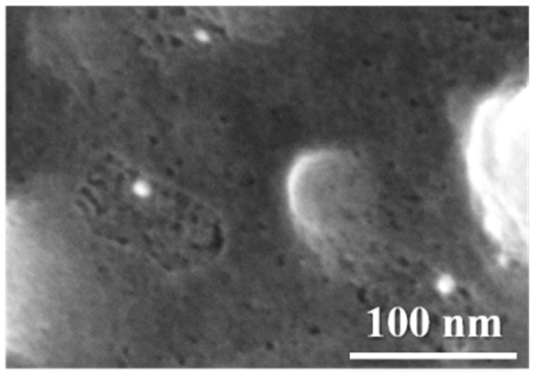

(c)

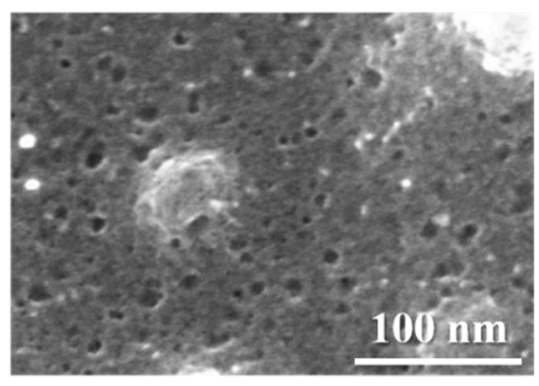

(b)

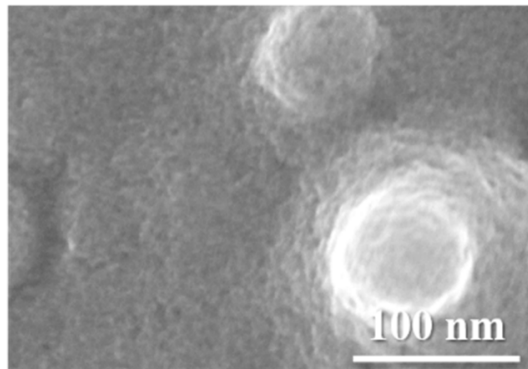

(d)

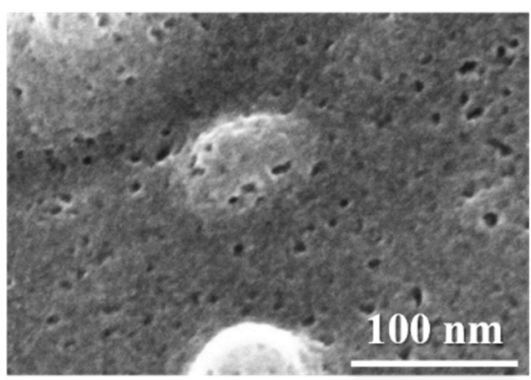

Figure 3. High-magnification scanning electron microscope images of films of woody carbon material. (a) Untreated surface. Vacuum-ultraviolet-treated films of woody carbon material at (b) high $P_{\mathrm{O} 2}$, (c) median $P_{\mathrm{O} 2}$, and (d) low $P_{\mathrm{O} 2}$.

$\mathrm{CO}_{2}$ adsorption isotherms for FWCMs, ranging $0-0.48$ relative pressure $\left(P / P_{0}\right)$, and pore size distribution analyzed from the adsorption isotherm are shown in Figure 4 . The adsorption amount increased dramatically at $P / P_{O}$ between $0-0.1$, and then saturated. This result indicated that micropores existed in the FWCMs and were successfully evaluated in this experiment [21]. There is no significant change between before and after the treatment. The specific surface areas and pore volumes of the micropores in the samples are summarized in Table 3. The average specific surface area of untreated FWCMs was $450 \mathrm{~m}^{2} / \mathrm{g}$, which was larger than that in a previous study $\left(216 \mathrm{~m}^{2} / \mathrm{g}\right)$ [8]. As noted above, $\mathrm{N}_{2}$ adsorption in the previous study did not reach an equilibrium state at $77 \mathrm{~K}$ because of the complex porous structure of natural woody carbon. The specific surface area and micropore volume at low $P_{\mathrm{O} 2}$ were slightly lower, while the other samples were unchanged. Note that the actual surface area was larger than the measured value because the formation of oxygen functional groups in the micropores affected $\mathrm{CO}_{2}$ adsorption [30]. The micropores grew into mesopores at low $P_{\mathrm{O} 2}$, resulting in a decrease in micropores, as discussed in the SEM section. We thought that the VUV effect occurs only at the outermost sample surface, and the effect might be covered by the results of inner part of the samples; thus, the rate of change was limited. In our future work, we plan to check the physical changes using other $\mathrm{AC}$, such as powder-type $\mathrm{AC}$, to clarify the change.

Table 3. Specific surface areas and pore volumes of untreated and vacuum-ultraviolet-treated films of woody carbon material estimated from $\mathrm{CO}_{2}$ Brunauer-Emmett-Teller micropore analysis.

\begin{tabular}{ccccc}
\hline \multirow{2}{*}{ Samples } & \multicolumn{2}{c}{ Specific Surface Area $\left[\mathbf{m}^{2} / \mathbf{g}\right]$} & \multicolumn{2}{c}{ Pore Volume $\left[\mathrm{cm}^{3} / \mathbf{g}\right]$} \\
\cline { 2 - 5 } & Untreated & Treated & Untreated & Treated \\
\hline High $P_{\mathrm{O} 2}$ & 450 & 450 & 0.26 & 0.26 \\
Middle $P_{\mathrm{O} 2}$ & 450 & 450 & 0.26 & 0.26 \\
Low $P_{\mathrm{O} 2}$ & 440 & 430 & 0.25 & 0.24 \\
\hline
\end{tabular}


(a)

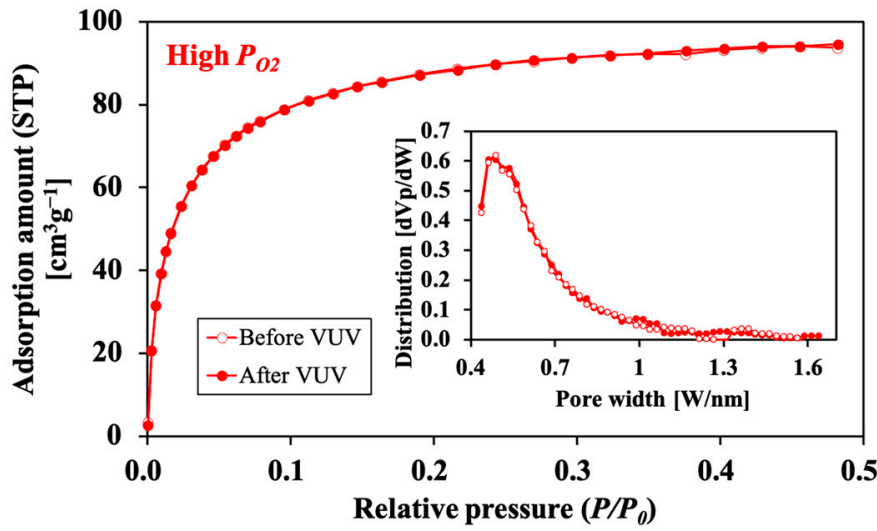

(b)

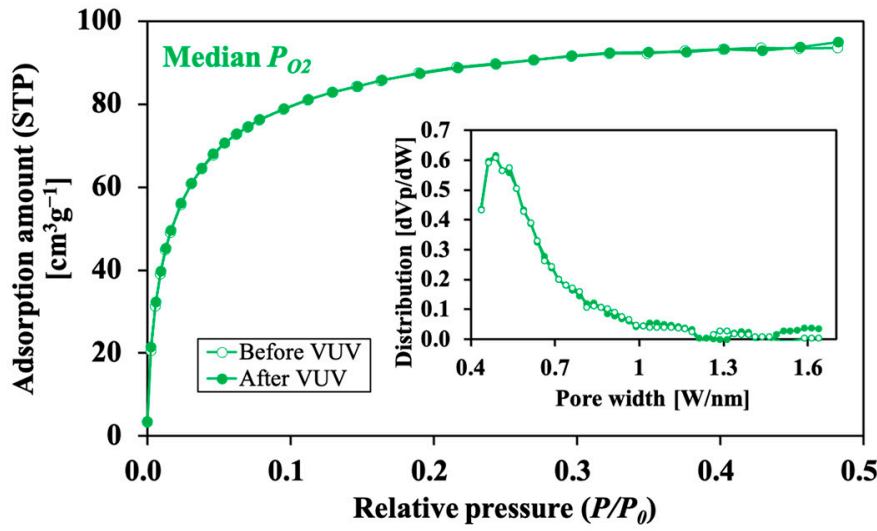

(c)

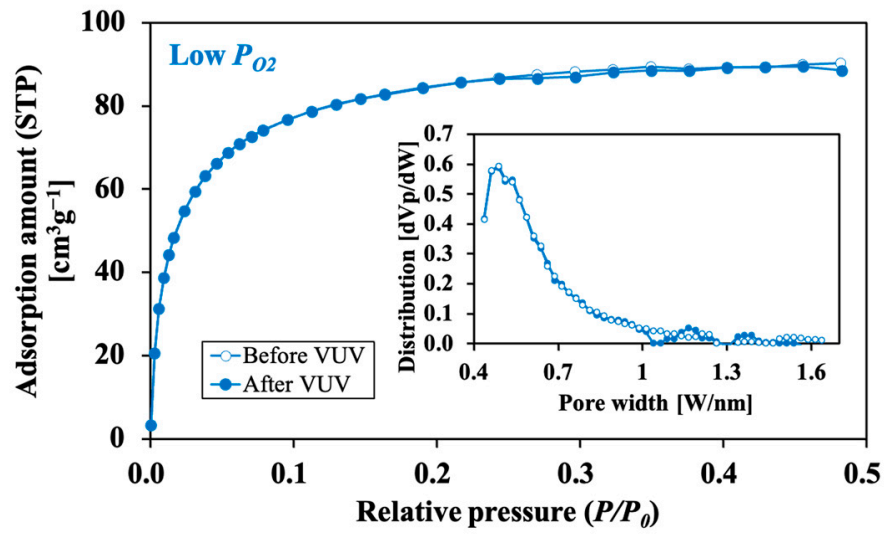

Figure 4. $\mathrm{CO}_{2}$ adsorption isotherms of films of woody carbon material from 0 to 0.48 relative pressure: (a) High $P_{\mathrm{O} 2}$ condition, (b) median $P_{\mathrm{O} 2}$ condition, (c) low $P_{\mathrm{O} 2}$ condition, and (d) all condition. Inset: Micropore distribution $\mathrm{dV}_{\mathrm{p}} / \mathrm{dW}$ analyzed by Horvath-Kawazoe method.

\subsection{Water Vapor Adsorption Characteristic}

Figure 5 shows the water adsorption capacities of untreated and treated FWCMs, silica-gel desiccant is used for reference. The adsorption rate of the silica-gel and the average rate of the untreated FWCMs were $12.3 \%$ and $19.4 \%$, respectively. Thus, the adsorption rates of untreated FWCMs were higher than that of silica gel. Moreover, the adsorption rate greatly increased after VUV treatments. In particular, the rate increased by $45.5 \%$ after the median $P_{\mathrm{O} 2}$ treatment, which was more than 1.4 times those following high $P_{\mathrm{O} 2}(12.2 \%)$ or low $P_{\mathrm{O} 2}(31.5 \%)$. We assumed that VUV treatment has the following effects on water adsorption capability: (i) Increment of surface oxygen functional group enhance the hydrophilicity of surface, and (ii) surface physical changes improve the specific surface area that is an important factor for water adsorption [21]. The specific surface at 
the outermost sample surface was increased by improving surface roughness caused by $\mathrm{O}_{3}$ effect in the high $P_{\mathrm{O} 2}$ treatment, and increasing the number of mesopores caused by the VUV light effect in the low $P_{\mathrm{O} 2}$ treatment. In addition, the FWCM surface after the median $P_{\mathrm{O} 2}$ treatment exhibited both an $\mathrm{O}_{3}$ effect, as for the high $P_{\mathrm{O} 2}$, and a VUV effect, as for the low $P_{\mathrm{O} 2}$. Hence, the VUV can increase the water adsorption capacity of the AC with an optimized $\mathrm{O}_{2}$ partial pressure.

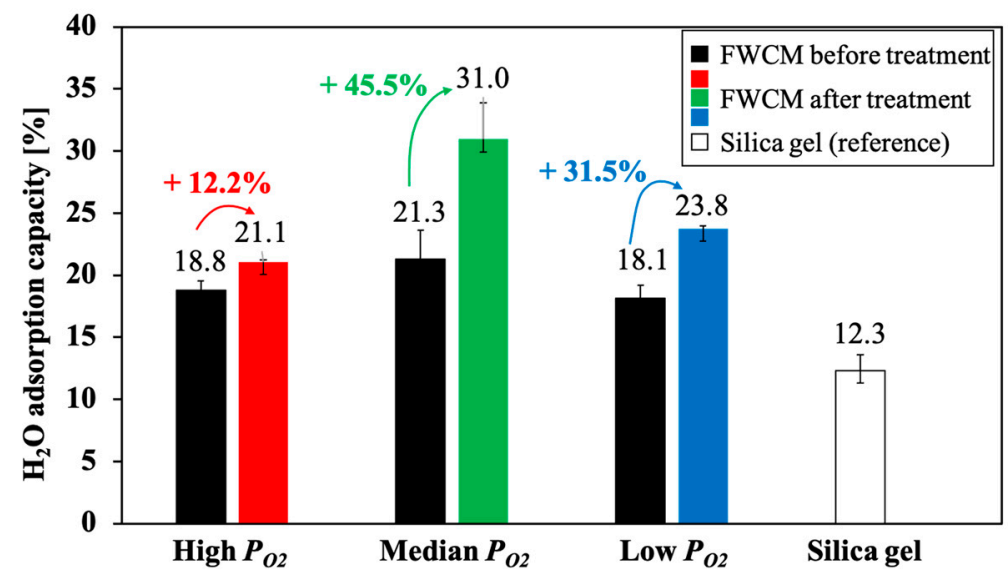

Figure 5. Water adsorption capacities of untreated and vacuum-ultraviolet-treated films of woody carbon material at $20 \%$ relative-humidity. Commercial silica-gel desiccant was also evaluated as a reference.

\section{Conclusions}

We studied $\mathrm{O}_{2}$ effects on the VUV treatment of AC by using three different $\mathrm{O}_{2}$ partial pressures that changed the generated $\mathrm{O}_{3} / \mathrm{VUV}$ light ratio. The chemical and physical effects of VUV on FWCM were characterized. Our results reveal that the chemical reaction sites on the AC changed with the $\mathrm{O}_{2}$ partial pressure. The reaction sites increased the surface roughness at high $P_{\mathrm{O} 2}$, and increased the mesopore sizes and numbers at low $P_{\mathrm{O} 2}$. The VUV at the median $P_{\mathrm{O} 2}$ significantly improved the water adsorption capacity $(45.5 \%)$, because both the roughness and the pore sizes and number increased. These results indicate that pore properties of wood-based AC can be controlled by VUV with an optimal $\mathrm{O}_{2}$ partial pressure for a wide range of applications.

Author Contributions: H.K. and S.M. conceived the idea and designed the experiments; N.T., H.K., and S.M. carried out the experiments; N.T. and H.K. wrote the manuscript; H.K., S.M., M.K., A.T., S.S. and J.M. revised the manuscript. All authors have read and agreed to the published version of the manuscript.

Funding: This research received no external funding.

Acknowledgments: The authors would like to acknowledge Sato (Durart Company, Saitama, Japan), Mizokami (Nippon API Corporation, Tokyo, Japan), and MEXT Nanotechnology Platform Support Project (Waseda University, Tokyo, Japan) for their support. We thank Alan Burns, from the Edanz Group for editing a draft of this manuscript.

Conflicts of Interest: The authors declare no competing interests.

\section{Appendix A}

Appendix A Figure A1 shows vacuum ultraviolet (VUV) light arrival rate in different $\mathrm{O}_{2}$ partial pressures used in this study. Arrival rate of VUV light is calculated by following Equation (A1) [20];

$$
I=I_{0} \times \exp \left(-\alpha P_{\mathrm{O} 2} L\right)
$$

where $I_{0}$ is the light intensity from the VUV source, $I$ is the VUV intensity on the sample surface, $\alpha$ is the VUV absorption efficiency of $\mathrm{O}_{2}, \mathrm{P}_{\mathrm{O} 2}$ is the $\mathrm{O}_{2}$ partial pressure, and $L$ is the 
distance from the light source to the sample. We calculated $\alpha$ as $2.0 \times 10^{-5} \mathrm{~Pa}^{-1} \mathrm{~mm}^{-1}$ [20] and $L$ as $1.3 \mathrm{~cm}$ [8] for this calculation. When $P_{\mathrm{O} 2}$ is $6.3 \times 10^{-6} \mathrm{~Pa}$ (low $P_{\mathrm{O} 2}$ condition), almost $100 \%$ of VUV light arrives to the sample surface, meaning VUV light energy directly reacts with the sample. On the other hand, when $P_{\mathrm{O} 2}$ is $5.0 \times 10^{4} \mathrm{~Pa}$ (high $P_{\mathrm{O} 2}$ condition), VUV light almost absorbed by $\mathrm{O}_{2}$ and hardly reaches the sample $\left(3.1 \times 10^{-4 \%}\right)$, meaning VUV light energy is used to generate $\mathrm{O}_{3}$ that react with the sample. When $P_{\mathrm{O} 2}$ is $1.9 \times 10^{3} \mathrm{~Pa}$ (median $P_{\mathrm{O} 2}$ condition), $60.7 \%$ of VUV light arrives to the sample, meaning both VUV light effect and $\mathrm{O}_{3}$ effect occurred.

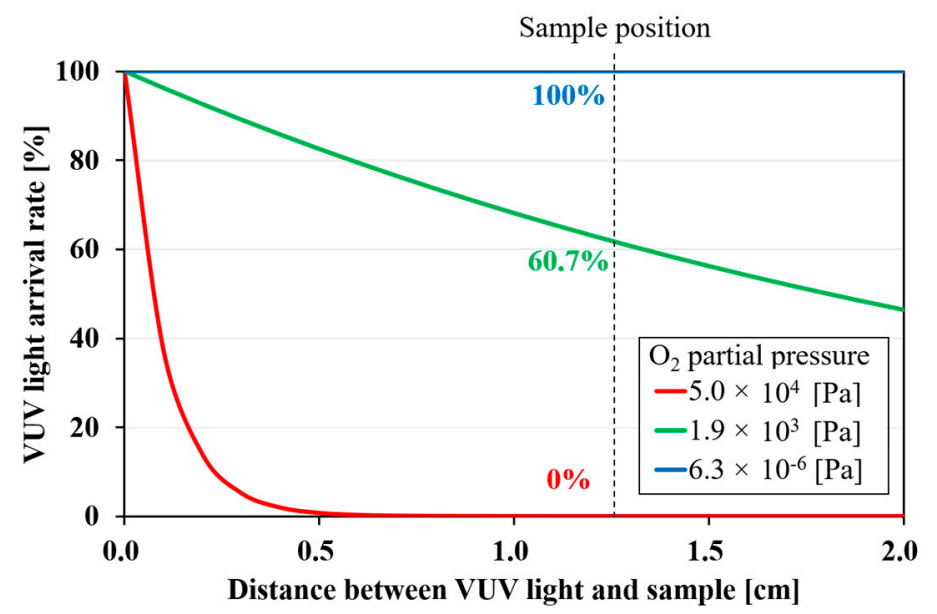

Figure A1. Calculation results of vacuum ultraviolet (172-nm) light arrival rate.

\section{References}

1. Ismadji, S.; Sudaryanto, Y.; Hartono, S.B.; Setiawan, L.E.K.; Ayucitra, A.J.B.T. Activated carbon from char obtained from vacuum pyrolysis of teak sawdust: Pore structure development and characterization. Bioresour. Technol. 2005, 96, 1364-1369. [CrossRef] [PubMed]

2. Hu, Z.; Srinivasan, M.P.; Ni, Y. Preparation of mesoporous high-surface-area activated carbon. Adv. Mater. 2000, 12, 62-65. [CrossRef]

3. Dias, J.M.; Alvim-Ferraz, M.C.; Almeida, M.F.; Rivera-Utrilla, J.; Sánchez-Polo, M. Waste materials for activated carbon preparation and its use in aqueous-phase treatment: A review. J. Environ. Manag. 2007, 85, 833-846. [CrossRef] [PubMed]

4. Bhatnagar, A.; Hogland, W.; Marques, M.; Sillanpää, M. An overview of the modification methods of activated carbon for its water treatment applications. Chem. Eng. J. 2013, 219, 499-511. [CrossRef]

5. De Jonge, R.J.; Breure, A.M.; van Andel, J.G. Bioregeneration of powdered activated carbon (PAC) loaded with aromatic compounds. Water Res. 1996, 30, 875-882. [CrossRef]

6. Inomata, K.; Kanazawa, K.; Urabe, Y.; Hosono, H.; Araki, T. Natural gas storage in activated carbon pellets without a binder. Carbon 2002, 40, 87-93. [CrossRef]

7. Maeda, S.; Kuwae, H.; Sakamoto, K.; Shoji, S.; Mizuno, J. Water-Electrokinetic Power Generation Device Using Flexible Woody Carbon Film. In 2019 IEEE 32nd International Conference on Micro Electro Electro Mechanical Systems (MEMS); IEEE: Seoul, Korea, January 2019; pp. 233-236. [CrossRef]

8. Funabashi, T.; Mizuno, J.; Sato, M.; Kitajima, M.; Matsuura, M.; Shoji, S. Film of lignocellulosic carbon material for self-supporting electrodes in electric double-layer capacitors. APL Mater. 2013, 1, 032104. [CrossRef]

9. Li, X.; Tang, Y.; Song, J.; Yang, W.; Wang, M.; Zhu, C.; Zhao, W.; Zheng, J.; Lin, Y. Self-supporting activated carbon/carbon nanotube/reduced graphene oxide flexible electrode for high performance supercapacitor. Carbon 2018, 129, 236-244. [CrossRef]

10. Yahya, M.A.; Al-Qodah, Z.; Ngah, C.W.Z. Agricultural bio-waste materials as potential sustainable precursors used for activated carbon production: A review. Renew. Sust. Energ. Rev. 2015, 46, 218-235. [CrossRef]

11. Zhu, H.; Luo, W.; Ciesielski, P.N.; Fang, Z.; Zhu, J.Y.; Henriksson, G.; Himmel, M.E.; Hu, L. Wood-derived materials for green electronics, biological devices, and energy applications. Chem. Rev. 2016, 116, 9305-9374. [CrossRef] [PubMed]

12. Álvarez-Merino, M.A.; López-Ramón, V.; Moreno-Castilla, C. A study of the static and dynamic adsorption of Zn (II) ions on carbon materials from aqueous solutions. J. Colloid Interface Sci. 2005, 288, 335-341. [CrossRef] [PubMed]

13. Jia, Y.F.; Thomas, K.M. Adsorption of cadmium ions on oxygen surface sites in activated carbon. Langmuir 2000, 16, 1114-1122. [CrossRef]

14. Macías-García, A.; Gómez-Serrano, V.; Alexandre-Franco, M.F.; Valenzuela-Calahorro, C. Adsorption of cadmium by sulphur dioxide treated activated carbon. J. Hazard. Mater. 2003, 103, 141-152. [CrossRef] 
15. Lee, D.; Hong, S.H.; Paek, K.H.; Ju, W.T. Adsorbability enhancement of activated carbon by dielectric barrier discharge plasma treatment. Surf. Coat. Technol. 2005, 200, 2277-2282. [CrossRef]

16. ChangMing, D.; DongWei, H.; HongXia, L.; MuDan, X.; Kui, W.; Lu, Z.; ZhiYi, L.; TengFei, C.; JianMin, M.; Dong, G.; et al. Adsorption of acid orange II from aqueous solution by plasma modified activated carbon fibers. Plasma Chem. Plasma Process. 2013, 33, 65-82. [CrossRef]

17. Li, Q.; Ding, W.; Yong, Y.; Zeng, X.; Gao, Y. Effects of ultraviolet modification on physicochemical property and adsorption performance of biochar. Nanosci. Nanotechnol. Lett. 2016, 8, 978-984. [CrossRef]

18. Peng, Z.; Liu, X.; Chen, H.; Liu, Q.; Tang, J. Characterization of ultraviolet-modified biochar from different feedstocks for enhanced removal of hexavalent chromium from water. Environ. Sci. Pollut. Res. 2018, 25, 10808-10819. [CrossRef]

19. Domingo-García, M.; López-Garzón, F.J. \& Pérez-Mendoza, M. Effect of some oxidation treatments on the textural characteristics and surface chemical nature of an activated carbon. J. Colloid Interface Sci. 2000, 222, 233-240.

20. Watanabe, K.; INN, E.C.Y.; Zelikoff, M. Absorption coefficients of oxygen in the vacuum ultraviolet. J. Chem. Phys. 1953, 21, 1026-1030. [CrossRef]

21. Marsh, H.; Reinoso, F.R. Chapter 4 Characterization of Activated Carbon. In Activated Carbon, 1st ed.; Elsevier Science: Amsterdam, The Netherlands, 2006; pp. 143-242.

22. Solomon, M.E. Control of humidity with potassium hydroxide, sulphuric acid, or other solutions. Bull. Entomol. Res. 1951, 42, 543-554. [CrossRef]

23. Carrott, P.J.M.; Carrott, M.M.L. Lignin-from natural adsorbent to activated carbon: A review. Bioresour. Technol. 2007, 98, 2301-2312.

24. Atkinson, R.; Carter, W.P.L. Kinetics and mechanisms of the gas-phase reactions of ozone with organic compounds under atmospheric conditions. Chem. Rev. 1984, 84, 437-470. [CrossRef]

25. Sajjadi, B.; Chen, W.Y.; Egiebor, N.O. A comprehensive review on physical activation of biochar for energy and environmental applications. Rev. Chem. Eng. 2019, 35, 735-776. [CrossRef]

26. Laine, N.R.; Vastola, F.J.; Walker, J.P.L. The importance of active surface area in the carbon-oxygen reaction ${ }^{1,2}$. J. Phys. Chem. 1963, 67, 2030-2034. [CrossRef]

27. Gómez-Serrano, V.; Álvarez, P.M.; Jaramillo, J.; Beltrán, F.J. Formation of oxygen complexes by ozonation of carbonaceous materials prepared from cherry stones: I. Thermal effects. Carbon 2002, 40, 513-522. [CrossRef]

28. Huang, H.; Huang, H.; Zhan, Y.; Liu, G.; Wang, X.; Lu, H.; Xiao, L.; Feng, Q.; Leung, D.Y. Efficient degradation of gaseous benzene by VUV photolysis combined with ozone-assisted catalytic oxidation: Performance and mechanism. Appl. Catal. B 2016, 186, 62-68. [CrossRef]

29. Kislov, V.V.; Nguyen, T.L.; Mebel, A.M.; Lin, S.H.; Smith, S.C. Photodissociation of benzene under collision-free conditions: An $a b$ initio/Rice-Ramsperger-Kassel-Marcus study. J. Chem. Phys. 2004, 120, 7008-7017. [CrossRef] [PubMed]

30. Song, X.; Liu, H.; Cheng, L.; Qu, Y. Surface modification of coconut-based activated carbon by liquid-phase oxidation and its effects on lead ion adsorption. Desalination 2010, 255, 78-83. [CrossRef] 